November 10, 1992

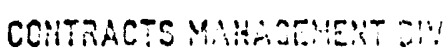

92 NOV 15 : : 11:05

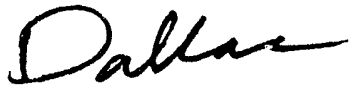

Universityof Idaho

College of Engineering

Department of Chemical Engıneering

Buchanan Engineering Laboratory 308

Moscow, Idaho 83843

Phone (208) 885.6793

Dallas L. Hoffer

U.S. Department of Energy

DOE/ER/13572--5

Idaho Field office

785 DOE Place, MS 1221

DE93 003595

Idaho Falls, Idaho 83401-1562

Dear Dallas:

Enclosed are two reports on our project entitled "Drop Oscillation and Mass Transfer in Electric Fields", \#FG07-86ER13572, that were prepared and sent to the Washington DOE office previously this year. I hope to have the forms you requested sent to you in a few days.

Best regards,

Dimwín Cibiz

Thomas E. Carleson

Professor

CC. R. Budwig

C. T. Tirms are attahed 
Robert S. Marianelli, Director

Division of Chemical Sciences

Office of Basic Energy Sciences

Department of Energy

Washington, DC 20585

Dear Dr. Marianelli:

Attached is an updated report outline describing our research conducted under the DOE. Contract FG07-86ER13572, "Drop Oscillation and Mass Transfer in Alternating Electric Fields". A current summary of our research is also attached. If you have any questions, please call (208-885-7652) or write me.

Sincerely yours,

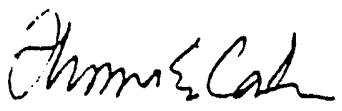

Thomas E. Carleson

Associate Frofessor 


\title{
Drop Oscillation and Mass Transfer in Altemating Electric Fields
}

Research Abstract 1990-1991

In certain cases droplet direct contact heat transfer rates can be significantly enhanced by the application of an alternating electric field. This field can produce shape oscillations in a droplet which will enhance mixing. The theoretical evaluation of the effect of the interaction of the field with drop charge on the hydrodynamics has been completed for small amplitude oscillations. Previous work with a zero order perturbation method was followed up with a first order perturbation method to evaluate the effect of drop distortion on drop charge and field distribution. The first order perturbation results show secondary drop oscillations of four modes and two frequencies in each mode. The miost significant secondary oscillation has the same mode and frequency as the second mode oscillation predicted from the first order perturbation work. The resonant frequency of all oscillations decrease with increasing electric field strength and drop charge. Work is currently underway to evaluate the heat transfer enhancement from an applied alternating electric field.

\section{DISCLAIMER}

\begin{abstract}
This report was prepared as an account of work sponsored by an agency of the United States Government. Neither the United States Gnvernment nor any agency thereof, nor any of their employees, makes any warranty, express or implied, or assumes any legal liability or responsibility for the accuracy, completeness, or usefulness of any information, apparatus, product, or process disclosed, or represents that its use would not infringe privately owned rights. Reference herein to any specific commercial product, process, or service by trade name, trademark, manufacturer, or otherwise does not necessarily constitute or imply its endorsement, recommendation, or favoring by the United States Gevernment or any agency thereof. The views and opinions of authors expressed herein do not necessarily state or reflect those of the United States Government or any agency thereof.
\end{abstract}




\section{University ofldaho}

Mechanical Engineering Departmen:

Moscow. Idaho 83843

208.885 .6579

June 25, 1992

Dr. John Burnett

ER-142

Basic Energy Sciences

U.S. Department of Energy

Washington, D.C. 20585

Dear Dr. Burnett:

Please find enclosed seven copies of a progress report for the project entitled, "The Behavior and Mass Transfer of Charged Droplet Swarms." I spoke with Tom on the phone yesterday. He is in Beijing through August 21, on a project sponsored by the NSF U.S.-China Cooperative Science Program. He can be reached by telephone at 011-86-1-890571, ext 517. The best time to call is $6: 30 \mathrm{pm}$ eastern daylight time (this is 7:30 am in Beijing). It is useful to have someone who speaks Chinese initiate the call in order to get through the operator.

I will phone next week to check with you on the enclosed material.

Sincerely,

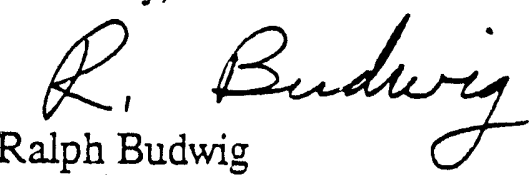

Associate Professor

Tel: $208-885-7454$

FAX: 208-885-9031 


\section{PROGRESS REPORT}

Project title:

Principal Investigator:

Performing organization:

Contract number:

D.O.E. program:

Type of report:

Report date:
Drop Oscillation and Mass Transfer in Alternating Electric Fields

Thomas E. Carleson

University of Idaho

Moscow, Idaho 83843

FG07-86ER13572

Basic Energy Sciences - Division of Chemical Sciences

Progress report

May 30, 1991 to June 1, 1992

June 24, 1992

1. Introduction

May, 1991: Work on a theoretical model for the electrohydrodynamics of a droplet undergoing small oscillations was completed (Yang and Carleson). The model was verified experimentally from visualizations of water droplet oscillations in a silicone oil continuous phase. These results have been disseminated in publications and presentations cited in section 4 , below.

\section{Research Summary}

Summer and Fall, 1991: Experimental work was initiated to conduct local heat transfer measurements in a heated oscillating droplet. The plan was to use thermochromic liquid crystal (TLC) particles to make local measurements of temperature in the droplet and continuous phases. After a number of preliminary experiments it was determined that the TLC particle method would not work because the particles caused electrical breakdown of the silicone oil continuous phase.

Spring, 1992: We explored alternative experimental methods suitable for local measurement of heat or mass transfer of droplets in the electrohydrodynamic apparatus. It was decided that the laser induced fluorescence (LIF) species concentration method would be used. In this method, a fluorescent dye that is soluble in both phases is used. The dye concentration in each phase is adjusted to allow either continuous phase or dispersed phase controlling mass transfer cases. As a droplet forms, a thin laser light sheet is used to excite the dye. Images of the fluoresced light intensity from the dye can then be used as a measure of the local, instantaneous concentration. The mass transfer 
coefficient for the dispersed and continuous phase is then determined from spatially averaged concentration measurements.

We have constructed the apparatus for LIF concentration measurements (see figure 1) and are currently performing preliminary experiments. The droplet phase consists of deionized, distilled water with a small amount of $\mathrm{NaCl}$ added to increase electrical conductivity and sucrose added to match the index of refraction between the droplet and continuous phase. The continuous phase is a mixture of hexariol and chloroform. The dye used is Rhodamine $B$ which absorbs light in the green range and fluoresces in the orange range.

Images of fluoresced light from the droplet and continuous phase are being recorded using a special video system. A Questar $Q M-1$ macro lens is used to resolve an area of $1 \mathrm{~cm}$ by $1 \mathrm{~cm}$ from a distance of $1 \mathrm{~m}$ from the front of the lens to the focal plane. The lens is mounted on a CIDTEC 2250, $512 \times 512$ pixel solid-state camera. The camera is designed for image processing applications with exposure time, frame rate, and trigger all controlled by a PC compatible computer. Exposure times can be set from less than a millisecond to several seconds. Image capture by the camera is synchronized to droplet oscillations by a TTL trigger signal. Each frame image can be viewed directly on a video monitor connected to the interface card and can be processed and stored by the computer. Local dye concentration is obtained from fluoresced light intensity measured at each pixel.

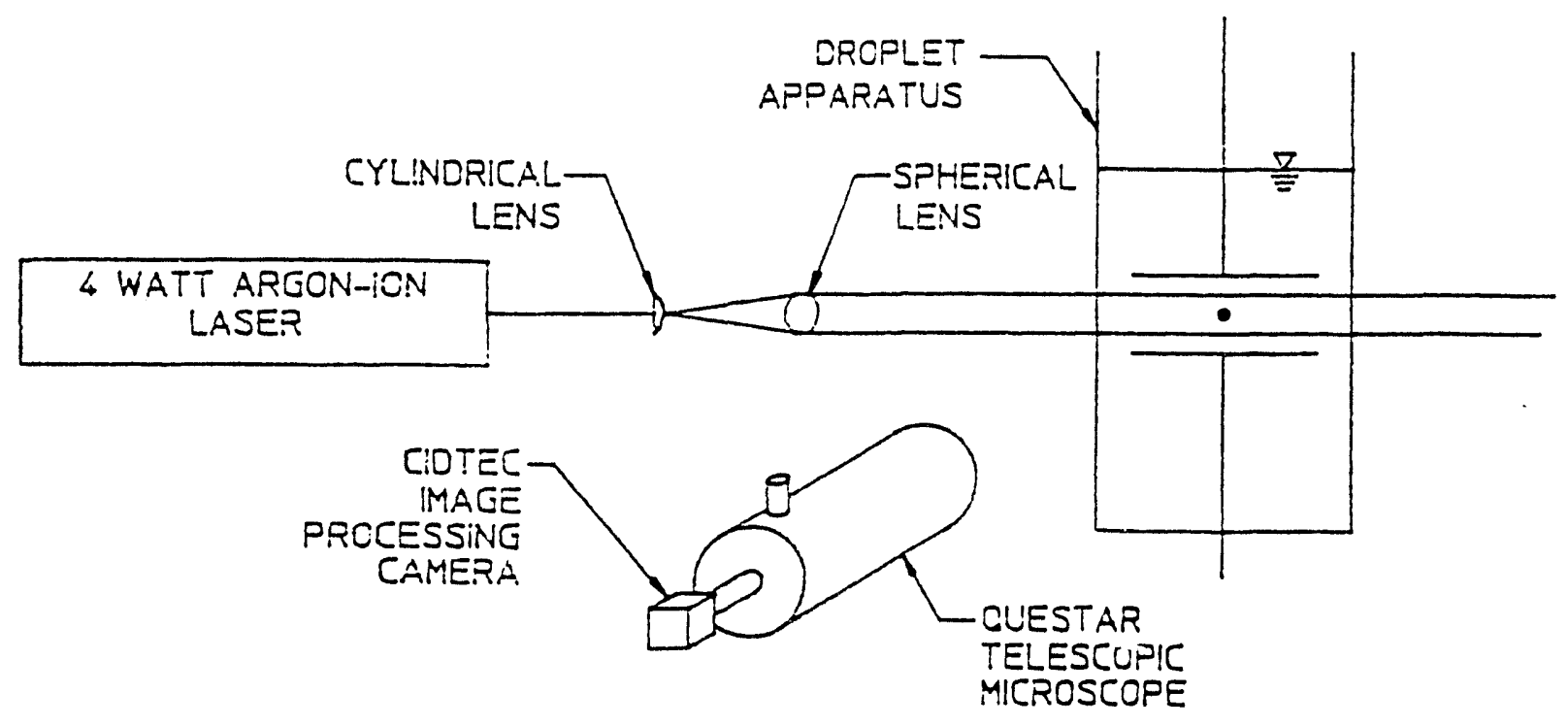

Figure 1. The experimental apparatus. 


\section{Personnel}

Wenrui Yang completed his Ph.D. in May, 1991. He initiated experimental work on droplet heat transfer measurements in Summer, 1991. Sudhakar Katamneni began his M.S. program in Fall, 1991. He conducted preliminary experiments to test the TLO particle method in Fall, 1991. In Spring, 1992, Ralph Budwig (Associate Professor of Mechanical Engineering, University of Idaho) and Sudhakar Katamneni began to work with the LIF method. In May, 1992, Kelly Williamson, a senior undergraduate student in chemical engineering, was added to the research team.

\section{Publications and Presentations}

Yang, W. and Carleson, T.E., "Secondary Oscillations of a Charged Drop in an Alternating Electric Field," Submitted to the J. Fluid Mech.

Yang, W. and Carleson, T.E., "Linear Oscillations of a Drop in Uniform Alternating Electric Fields," AIChE J. Vol. 37, No. 1, 1601 (1991).

Yang, W. and Carleson, T.E., "Secondary Oscillations of a Charged Drop in an Alternating Electric Field, "Presented at the AIChE 1991 Annual Meeting.

Yang, W., "Oscillations of a Charged Drop in an Alternating Electric Field," Ph.D. dissertation, University of Idaho, May, 1991.

Yang, W. and Carleson, T.E., "Linear Oscillations of a Drop in Uniform Alternating Electric Fields," Presented at the AlChE 1990 Annual Meeting, paper 2598.

Yang, W. and Carleson, "Several Effects of Electric Fields on Liquid Extraction," IEEE Transactions on Industry Applications, Vol. 26, No. 2, 366 (1990).

\section{Work Plan for Summer and Fall, 1992}

June: Set-up and learn to use image processing hardware and software. Develop droplet and continuous phases with matched index of refraction and density.

July: Measure extinction coefficient of Rhodamine B dye in continuous phase. Obtain qualitative images of spatial and temporal concentration in a stationary droplet and in an oscillating droplet. Develop calibration procedure for concentration versus fluoresced light intensity.

August: Calibrate continuous and droplet phase dye solutions. Perform quantitative measurements of concentration distributions in a stationary and oscillating droplet.

September to December: Complete quantitative measurements and write manuscript on methods and results. 

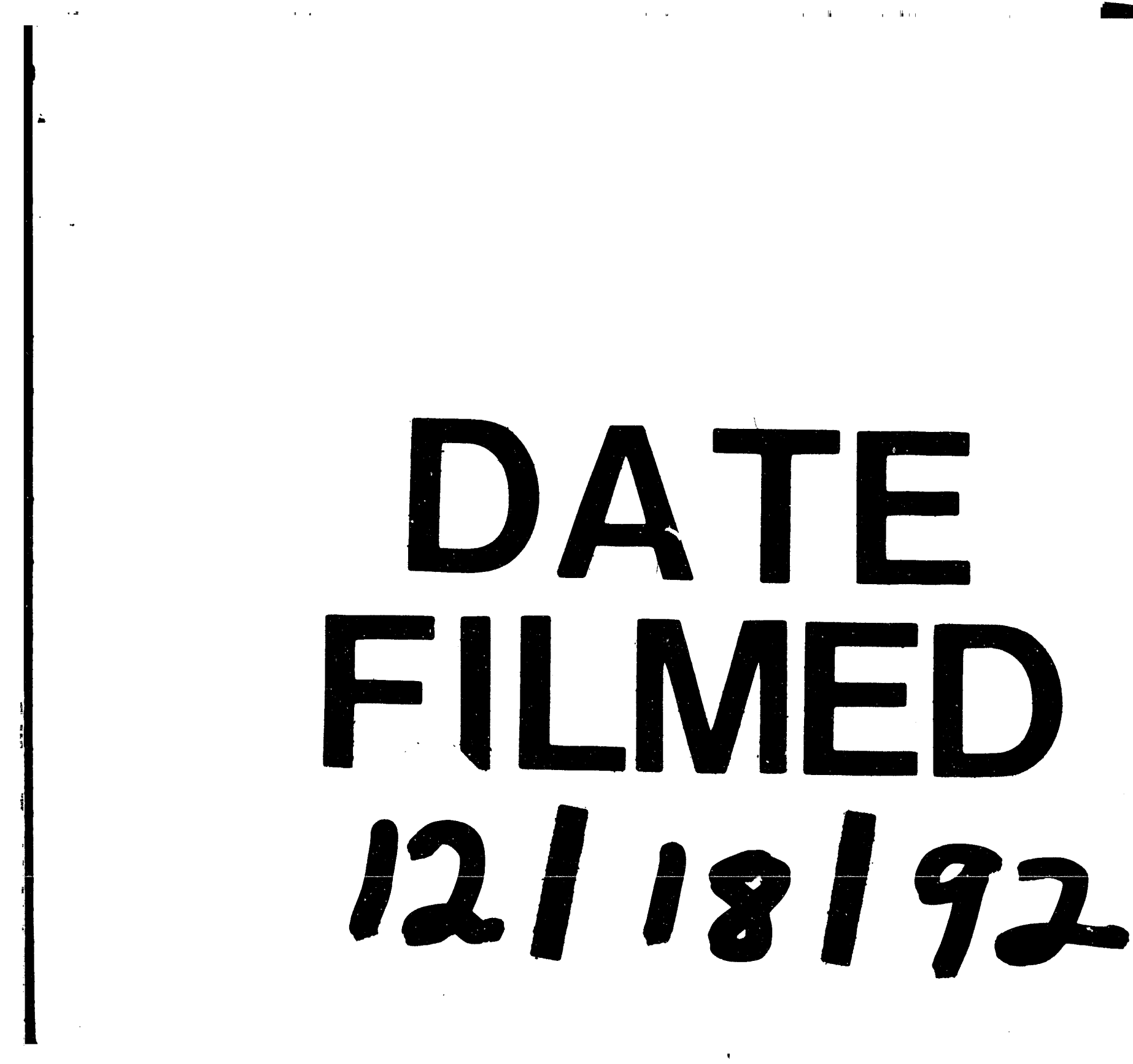
